\title{
Tuberculosis among the homeless at a temporary shelter in London: report of a chest
} $x$ ray screening programme

\author{
D Kumar, KM Citron, J Leese, J M Watson
}

\begin{abstract}
Study objective - To estimate the prevalence of active pulmonary tuberculosis in a homeless population in London and to assess whether those with suspected disease could be integrated into the existing health care system for further follow up and treatment.
\end{abstract}

Design - Voluntary screening programme based on a questionnaire survey and chest $x$ ray.

Setting and cases - Screening programmes were set up over the Christmas period in 1992 and 1993 at a shelter for the homeless in London. An offer of screening was made to all individuals who visited the centre and an interviewer administered questionnaire was completed on those who volunteered for the screening. Chest $x$ rays were carried out, developed, and read on site. Individuals with chest $\boldsymbol{x}$ ray features suggestive of tuberculosis or other medical problems were referred to a hospital of their choice.

Results and outcome - In 1992 nearly 1600 people visited the centre, of whom 372 volunteered for the screening and 342 were $x$ rayed. Nineteen of the $342(5 \cdot 6 \%)$ had radiological features suggestive of active tuberculosis. In 1993 around 2000 homeless people visited the centre, of whom 270 volunteered for the screening and 253 were $x$ rayed. Eleven $(4 \cdot 3 \%)$ had features consistent with active tuberculosis on the basis of the chest $x$ rays and clinical examination by a chest physician. Overall, of 595 people $x$ rayed in the two surveys, $30(5 \%)$ had changes suggestive of active tuberculosis. Further investigations confirmed nine $(1 \cdot 5 \%)$ with active pulmonary disease and eight with no active tuberculosis. In 13, the diagnosis was not determined as four declined further investigation and nine did not attend their hospital appointment.

Conclusions - Tuberculosis among the homeless remains a cause for concern. Follow up and treatment present unique difficulties. Services for the homeless need to include mechanisms for timely diagnosis and monitored treatment. Control programmes designed for the needs of the homeless are required.

\section{( $(\mathcal{E}$ Epidemiol Community Health 1995;49:629-633)}

In the 70 years from 1913-83, annual notifications of tuberculosis fell in England and
Wales from 117139 to 6803 . Since 1987, however, these have increased by an average of 3\% (range 4-7\%) annually. ${ }^{1}$ Several factors have been suggested as possible causes for this recent increase including ageing of the white population, an increase in the notifications from the Indian subcontinent group, and the human immunodeficiency virus (HIV) epidemic. An increase in homelessness has also been implicated in the rise in tuberculosis notifications. ${ }^{2}$ In the United States, tuberculosis among the homeless and residents of lodging houses and night shelters has been recognised as an important public health problem, ${ }^{3-5}$ which is further exacerbated by HIV infection and outbreaks of multi-drug resistant strains of tuberculosis in this population group. ${ }^{6-9}$ Reliable estimates of prevalence or incidence of tuberculosis among the homeless are not available for England and Wales and the contribution, if any, of this population group to the recent increase in tuberculosis notifications is not known.

The "homeless" are a diverse group: the common shared element is lack of a permanent dwelling place. The statutory homeless are those for whom the local authorities accept responsibility for housing. They are usually single parent families and families with young children. The potentially homeless are those (usually young adults and couples) who are living with relatives or friends and would like to live independently but lack the means to do so. Traditional travelling people, including the "new age travellers" and those living in caravans, are also classified as homeless. The two groups most likely to have health problems are the hostel dwellers, which includes individuals living in short and long term hostels, and those who can be classified as having "no fixed abode" that is, street people who sleep rough or are squatters and who may occasionally use temporary hostels and night shelters. These are usually single men who are socially isolated and often suffer from psychiatric problems and alcoholism. The numbers of homeless within each category are difficult to assess and the estimates vary depending on which categories are selected. A survey in 1989 reported that around 75000 people were homeless in London - of whom 2000 slept rough, 18000 lived in hostels, 25000 lived in hotels, and 30000 lived in squats. ${ }^{10}$ Around 5000 homeless people ("statutory" and those with "no fixed abode") are estimated to be living in the north east Westminster area of London alone. ${ }^{11}$ Estimates of the numbers of hostel dwellers and those with "no fixed abode" vary considerably. The 
1991 census reported that 2703 slept rough in Britain on census night, ${ }^{12}$ of whom 1197 were in London, but the housing charity Shelter estimated that 8000 individuals sleep rough in Britain every night, representing about 20000 who may sleep rough from time to time. ${ }^{13}$

Each year the charity Crisis sets up temporary shelters for the homeless during Christmas, as many hostels and shelters close down during this period. The shelters provide accommodation, meals, basic facilities, and medical care. They attract a large number of homeless people with "no fixed abode" - that is, those sleeping rough, squatters, and night shelter users. These shelters presented an opportunity to provide a screening programme to a population which would otherwise be inaccessible. During Christmas of 1992 and 1993 voluntary $x$ ray screening programmes for tuberculosis were set up at the main temporary shelter in London to assess the prevalence of respiratory tuberculosis among these homeless people and to see how many of those detected could be integrated into the existing health care system.

\section{Methods}

A chest $x$ ray facility was set up at the shelter. The screening for tuberculosis was advertised through posters, leaflets, and regular public announcements at the site. An interviewer administered questionnaire was completed for all those who volunteered for the screening. In 1992 individuals were selected for a chest $x$ ray on the basis of their symptoms. Volunteers who complained of any one of the following were referred for a chest $x$ ray:

- Feeling of being unwell for more than two consecutive weeks in the last three months;

- History of cough for more than two weeks in the last three months;

Table 1 Sociodemographic characteristics of the study population

\begin{tabular}{|c|c|c|c|c|}
\hline & $\begin{array}{l}1992 \\
\text { No }\end{array}$ & $(\%)$ & $\begin{array}{l}1993 \\
\mathrm{No}\end{array}$ & $(\%)$ \\
\hline $\begin{array}{l}\text { Age (y): } \\
15-29 \\
30-44 \\
45-59 \\
60-74 \\
>75 \\
\text { Mean (SD) }\end{array}$ & $\begin{array}{r}75 \\
151 \\
115 \\
30 \\
1 \\
41\end{array}$ & $\begin{array}{l}(20) \\
(41) \\
(31) \\
(8) \\
(12 \cdot 5)\end{array}$ & $\begin{array}{r}42 \\
92 \\
102 \\
32 \\
2 \\
44\end{array}$ & $\begin{array}{l}(16) \\
(34) \\
(38) \\
(12) \\
(1) \\
(13)\end{array}$ \\
\hline $\begin{array}{l}\text { Sex: } \\
\text { Men } \\
\text { Women }\end{array}$ & $\begin{array}{r}349 \\
23\end{array}$ & $\begin{array}{r}(94) \\
(6)\end{array}$ & $\begin{array}{r}225 \\
15\end{array}$ & $\begin{array}{r}(94) \\
(6)\end{array}$ \\
\hline $\begin{array}{l}\text { Country of birth: } \\
\text { England } \\
\text { Ireland } \\
\text { Scotland } \\
\text { Wales } \\
\text { Other } \\
\text { Missing }\end{array}$ & $\begin{array}{r}194 \\
82 \\
53 \\
1 \\
22 \\
11\end{array}$ & $\begin{array}{r}(52) \\
(22) \\
(14) \\
(3) \\
(6) \\
(3)\end{array}$ & $\begin{array}{r}138 \\
66 \\
37 \\
5 \\
21 \\
3\end{array}$ & $\begin{array}{r}(51) \\
(24) \\
(14) \\
(2) \\
(8) \\
(1)\end{array}$ \\
\hline $\begin{array}{l}\text { Accommodation: } \\
\text { "No fixed abode" } \\
\text { Hostel dwellers } \\
\text { Statutory \& potentially homeless } \\
\text { Living in caravans } \\
\text { Did not disclose }\end{array}$ & $\begin{array}{r}171 \\
99 \\
96 \\
3 \\
3\end{array}$ & $\begin{array}{r}(46) \\
(27) \\
(26) \\
(1) \\
(1)\end{array}$ & $\begin{array}{r}133 \\
47 \\
88 \\
-1\end{array}$ & $\begin{array}{c}(49) \\
(14) \\
(33) \\
- \\
-\end{array}$ \\
\hline Contact address given: & 260 & $(70)$ & 210 & (80) \\
\hline Registered with a general practitioner: & \multicolumn{2}{|c|}{$\overline{\mathrm{n}=372}$} & \multicolumn{2}{|c|}{$\begin{array}{l}163 \\
\mathrm{n}=270\end{array}$} \\
\hline
\end{tabular}

- Recent weight loss;

- History of haemoptysis; and

- History of contact with a case of tuberculosis.

In 1993 anyone who volunteered for the screening was offered a chest $x$ ray after completion of the questionnaire. In addition, in 1993 an attempt was made to collect sputum specimens for direct microscopy and culture from those who complained of productive cough.

A mobile $x$ ray machine was used to carry out full sized chest $x$ rays which were developed on-site. In 1992 the $x$ rays were read by either a consultant radiologist or a consultant chest physician. In 1993 the chest $x$ rays were examined by consultant chest physicians who also carried out clinical examinations on subjects who had chest $x$ ray features suggestive of tuberculosis. Those who required medical attention for conditions other than suspected tuberculosis were referred to the shelter's medical team. In 1992 all cases who had chest $x$ ray features suggestive of active tuberculosis were escorted by a volunteer to a hospital of their choice, where they were referred to the duty medical team which, in most instances, arranged a subsequent outpatient appointment. In 1993 cases were referred to consultant chest physicians at one of four major London hospitals with whom prior arrangements had been made. Hospital admission was arranged for those who required immediate attention and for others subsequent outpatient appointments were set up. Follow up information was obtained by contacting the referral hospital and through a network of general practitioners working closely with the homeless in London. The names of the individuals who were $x$ rayed in 1992 were compared with those in 1993 to identify duplicates.

\section{Results}

Nearly 1600 individuals visited the shelter in 1992 and about 2000 in 1993. During the first year, $372(23 \%)$ volunteered for the screening, of whom, on the basis of the criteria set in the questionnaire, 364 were eligible for a chest $x$ ray. A total of 342 chest $x$ rays were carried out as some individuals subsequently declined. During the second year 270 (14\%) volunteered for screening, 17 subsequently declined the $x$ ray examination and thus 253 chest $x$ rays were carried out. Comparison of the two study groups showed that none of those $x$ rayed in 1992 were $x$ rayed again in 1993.

The study population had very similar sociodemographic characteristics on both occasions (table 1). The individuals who volunteered for screening were aged between 16 and 76 years (mean 41 years). More than half of the participants $(52 \%)$ were born in England, while $23 \%$ were of Irish and $14 \%$ of Scottish origin. Very few of the participants (three in 1992 and two in 1993) were of non-white ethnic origin. Forty six per cent of the participants could be classified as having "no fixed abode" - that is, they were either sleeping rough, squatters, or occasional night shelter users - and $27 \%$ had been residents of long or short term hostels 
Table 2 Health related behaviour and medical history

\begin{tabular}{lcccc}
\hline & 1992 & & 1993 & \\
& $N o$ & $(\%)$ & $N o$ & $(\%)$ \\
\hline Smoking & 327 & $(88)$ & 218 & $(81)$ \\
Feeling unwell: & & & & \\
$\quad$ At the time & 229 & $(62)$ & 131 & $(49)$ \\
$\quad$ For more than two weeks in the last three months & 209 & $(56)$ & 133 & $(49)$ \\
Weight loss: & & & & \\
$\quad$ A little & 73 & $(20)$ & 48 & $(18)$ \\
A lot & 84 & $(23)$ & 64 & $(24)$ \\
Cough: & & & & \\
$\quad \begin{array}{l}\text { Dry } \\
\text { Productive }\end{array}$ & 34 & $(9)$ & 17 & $(6)$ \\
Haemoptysis & 207 & $(56)$ & 132 & $(49)$ \\
Previous lung disease: & 82 & $(22)$ & 44 & $(16)$ \\
$\quad$ Any & & & & \\
$\quad$ Tuberculosis & 97 & $(26)$ & 66 & $(24)$ \\
$\quad$ Chronic obstructive pulmonary disease & 19 & $(5)$ & 11 & $(4)$ \\
History of contact & 54 & $(15)$ & 33 & $(12)$ \\
& 54 & $(15)$ & 43 & $(16)$ \\
\hline
\end{tabular}

Table 3 Health problems reported by the study population

\begin{tabular}{|c|c|c|c|c|}
\hline Problems & $\begin{array}{l}1992 \\
\text { No }\end{array}$ & $(\%)$ & $\begin{array}{l}1993 \\
\text { No }\end{array}$ & $(\%)$ \\
\hline $\begin{array}{l}\text { Respiratory (all): } \\
\text { Chronic obstructive pulmonary disease } \\
\text { Tuberculosis } \\
\text { Pneumonia } \\
\text { Others } \\
\text { Cardiovascular } \\
\text { Gastrointestinal } \\
\text { Mental illnesses } \\
\text { Injuries } \\
\text { Arthritis } \\
\text { Genitourinary } \\
\text { Endocrinal } \\
\text { Skin }\end{array}$ & $\begin{array}{r}95 \\
19 \\
8 \\
54 \\
14 \\
- \\
- \\
- \\
- \\
- \\
- \\
\bar{n}=37\end{array}$ & $\begin{array}{r}(26) \\
(5) \\
(2) \\
(15) \\
(4) \\
= \\
- \\
- \\
- \\
- \\
- \\
-\end{array}$ & $\begin{array}{c}66 \\
11 \\
10 \\
33 \\
12 \\
29 \\
20 \\
19 \\
14 \\
12 \\
10 \\
8 \\
3 \\
\mathrm{n}=2\end{array}$ & $\begin{array}{r}(24) \\
(4) \\
(4) \\
(12) \\
(4) \\
(11) \\
(7) \\
(7) \\
(5) \\
(4) \\
(4) \\
(3) \\
(1)\end{array}$ \\
\hline
\end{tabular}

Table 4 Radiological findings on chest $x$ rays

\begin{tabular}{|c|c|c|c|c|}
\hline & $\begin{array}{l}1992 \\
\text { No }\end{array}$ & $(\%)$ & $\begin{array}{l}1993 \\
\text { No }\end{array}$ & $(\%)$ \\
\hline $\begin{array}{l}\text { Normal } \\
\text { Abnormal }\end{array}$ & $\begin{array}{r}263 \\
79\end{array}$ & (23) & $\begin{array}{r}191 \\
62\end{array}$ & $(24 \cdot 5)$ \\
\hline \multicolumn{5}{|l|}{ Tuberculosis: } \\
\hline Active & 19 & $(5 \cdot 6)$ & 11 & $(4 \cdot 3)$ \\
\hline Old & 6 & $(1 \cdot 8)$ & 13 & $(5 \cdot 1)$ \\
\hline Pneumonia & 4 & - & & \\
\hline Chronic obstructive pulmonary disease & 13 & & 3 & \\
\hline Bronchogenic carcinomas & 1 & & 1 & \\
\hline Cardiomegaly & 6 & & 2 & \\
\hline Rib fracture & 20 & & 25 & \\
\hline Clavicle fracture & 5 & & 2 & \\
\hline Scoliosis & 2 & & 4 & \\
\hline \multirow[t]{2}{*}{ Sarcoidosis } & 1 & & 1 & \\
\hline & $\mathrm{n}=342$ & & $\mathrm{n}=\mathbf{2 5 3}$ & \\
\hline
\end{tabular}

before coming to the shelter. Surprisingly, 70$80 \%$ of the participants gave the address of a friend, relative, or general practitioner through whom they could be contacted in future. In 1993 the participants were also asked if they were registered with a general practitioner: $60 \%$ were. Eighty eight per cent of the volunteers gave a history of smoking cigarettes regularly (table 2). Many complained of being generally unwell, having weight loss or a productive cough. Around one quarter gave a history of previous lung disease, $4-5 \%$ gave a past history of tuberculosis, and $15-16 \%$ of the participants gave a history of contact with a case of tuberculosis. A history of alcohol intake was sought only in 1993. Some 190 (71\%) gave a history of regularly consuming alcohol and $67(25 \%)$ denied alcohol consumption. Alcohol intake was quantified for 125 individuals. Of these, nine $(7 \%)$ had not consumed alcohol in the previous week, $47(38 \%)$ had consumed less than 21 units, $15(12 \%)$ had consumed the equivalent to 22-35 units of alcohol, and 54 $(43 \%)$ admitted to heavy drinking ranging from 36-210 units in the previous week.

In 1993 the participants were also asked about their general health problems (table 3 ) (in 1992 only information on previous lung disease was requested). Problems related to the respiratory system were the most common followed by cardiovascular, gastrointestinal, and mental illnesses.

Seventy nine (23\%) volunteers in 1992 and $62(24.5 \%)$ in 1993 had radiological evidence of an intrathoracic abnormality (table 4). In $1992,19(5 \cdot 4 \%)$ of those $x$ rayed had chest $x$ ray features suggestive of active tuberculosis and another six (2\%) had features suggestive of old tuberculosis.

In $1993,11(4 \cdot 3 \%)$ cases were suspected of suffering from active tuberculosis on the basis of the chest $x$ ray findings and clinical examination. A further $13(5 \cdot 1 \%)$ had radiological evidence of old inactive tuberculosis. Other abnormalities found in both years included rib fractures, bronchogenic carcinoma, pneumonia, chronic obstructive pulmonary disease, and cardiomegaly (table 4 ).

In 1992 , of the 19 cases who had chest $x$ ray features suggestive of active tuberculosis, two declined referral to hospital (one of these had radiological features suggestive of miliary tuberculosis). No record of hospital attendance has been traced for seven. In five cases active tuberculosis was excluded; four had evidence of old tuberculosis and one had an opportunist mycobacterial infection. Active tuberculosis was confirmed in five $(1.5 \% ; 95 \%$ confidence interval (CI): $0 \cdot 5 \%, 3.4 \%)$ cases. In 1993, 11 cases had features suggestive of active tuberculosis, of whom two declined referral. Two cases failed to attend their hospital appointment and their diagnosis could not be confirmed. Active tuberculosis has been confirmed in four $(1.6 \%$; $95 \%$ CI: $0.4 \%, 4.0 \%)$. Two of these were sputum smear positive and both had evidence of advanced cavitatory lesions on chest $x$ rays. A total of 77 sputum specimens were collected from volunteers who complained of a productive cough. Many of the specimens were of poor quality and none were smear or culture positive for Mycobacterium tuberculosis.

The nine confirmed cases from the two screening programmes were all men aged between 38 and 54 years. Five had "no fixed abode" and had been living on the streets before coming to the shelter, two lived in hostels, and two lived in a friend's flat. Three of the confirmed cases were English, four were Irish, one was Scottish and one was Welsh. Of these nine cases, only four were notified to the proper officer - that is, the Consultant in Communicable Disease Control of the district in which the patient received treatment.

Only three of the five cases in 1992 and two of the four cases confirmed in 1993 completed their treatment for tuberculosis; the remainder were lost to follow up. 


\section{Discussion}

THE PREVALENCE OF TUBERCULOSIS

The proportion of cases confirmed with active tuberculosis among the volunteers was $1.5 \%$ (95\% CI: $0.7 \%, 2.9 \%)$ - equivalent to a rate of 1500 per 100000 radiographs. Since these figures represent confirmed cases only, they are likely to be conservative estimates due to the high numbers who had $x$ ray features suggestive of tuberculosis but were lost to follow up (nine in 1992 and four 1993). In 1993, two of the four cases lost to follow up were strongly suspected of suffering from active tuberculosis on the basis of $x$ ray findings and clinical examination carried out by chest physicians at the screening site. Inactive pulmonary tuberculosis was diagnosed in 3\% in 1992 and $6 \%$ in 1993 (20 on initial screening and seven after hospital investigation). This high prevalence of inactive tuberculosis is important as the risk of reactivation may be increased due to the impoverished living conditions and poor nutritional status often found among the homeless with no fixed abode.

The rate of active tuberculosis in our survey was 1500 per 100000 radiographs (nine cases in 595 radiographs) and was similar to that found in radiological surveys of hostel dwellers during the past 30 years. In Edinburgh rates in the hostel dwellers were 1264 per 100000 (54 cases in 4269 radiographs) in 1968-75, and 896 per 100000 (42 cases in 4687 radiographs) in 1976-82. The uptake of screening in this survey varied between $26 \%$ and $64 \%{ }^{14}$ In Glasgow the rate was 1456 per 100000 (133 cases in 9132 radiographs) in 1978-82 (the uptake of screening in this survey before inducements was $12 \%$, but increased to $47 \%$ after the offer of inducements). ${ }^{15}$ This rate was 45 times greater than in heavy manual workers and 160 times greater than in school teachers surveyed by mass radiography during the same years. Moreover the severity of the disease and the mortality is greater in hostel dwellers among whom the spread of infection is encouraged by overcrowding. ${ }^{16}$

\section{STUDY POPULATION}

The study population was a self selected group who volunteered for screening. The uptake of screening ( $25 \%$ in 1992 and $14 \%$ in 1993) was low. No inducements were offered in this study. Inducements have been shown to greatly improve the uptake of screening. ${ }^{15}$ Nevertheless radiographic screening of hostels in London in 1989 using inducements failed to find any new cases of active tuberculosis. ${ }^{17}$ In our study most residents of the shelter did not accept screening and their rate of tuberculosis cannot be assumed to be the same as that in those who were screened. Furthermore the homeless who visit the Christmas shelter are not typical of the general homeless population in London since the shelter attracts a high proportion of street dwellers and squatters - that is, those with "no fixed abode". These rates cannot therefore be applied to all the homeless which include the "statutory" and the "potentially" homeless.
FOLLOW UP AND MANAGEMENT

This study highlighted the difficulty of follow up of homeless people. In 1992 seven of the 19 cases failed to keep their appointments and were lost to follow up. In 1993 prior arrangements were made with four major London hospitals for cases to be seen on the day they were detected by the screening. Hospital admission could only be arranged for two cases. In both tuberculosis was confirmed. An outpatient appointment was arranged for nine cases of whom four failed to attend and were lost to follow up. A better outcome might have resulted if these cases had received immediate hospital admission for further investigation but this may be difficult especially during the Christmas period when hospital services and bed numbers may be reduced. Management of the suspected cases could have been improved by supervision by general practitioners or designated community workers in liaison with hospitals.

The homeless frequently fail to comply with chemotherapy regimens. ${ }^{1418}$ Only five of the nine cases in this study completed six months chemotherapy. A poorly implemented treatment programme can lead to worsening of the tuberculosis problem and the spread of multiple drug resistant disease which can be disastrous for the patients and their contacts.

A problem envisaged for hospital managers was determining which district health authority should be billed for the treatment of homeless people who do not have a permanent address. Under new funding arrangements within the National Health Service, whereby district health authorities receive funds on a weighted capitation basis, those district health authorities with large homeless populations should be provided with additional support. However, the high mobility of this population makes their enumeration difficult. One option would be to set up a central funding mechanism for primary and secondary care for the health problems of the homeless, including tuberculosis.

The following measures are suggested to address the problems of tuberculosis among the homeless. We are aware that some are already used in homeless communities.

- Surveillance. The prevalence of tuberculosis among the different subgroups of the homeless needs further assessment. This would allow targeting of appropriate measures against tuberculosis in these groups.

- Case detection. Staff and residents at hostels and shelters for the homeless need education about the symptoms of tuberculosis and the action required for diagnosis and treatment of suspected cases. Open access clinics in hospitals and general practitioner clinics in hostels should be considered. Regular active case finding through screening at shelters and hostels needs to be evaluated. Collaboration is required with outreach community workers and non-governmental agencies.

- Case management. To ensure regular intake and completion of treatment, directly observed therapy should be established in col- 
laboration with agencies working with homeless people. A network is required which can offer a choice of different treatment options for the patients on terms acceptable to the homeless. Incentives in the form of food and travel vouchers should be considered to encourage individuals to return for treatment. ${ }^{19}$

- Contact tracing and prevention. Contact may prove difficult among rough-sleepers and residents of shelters and short-term hostels because of their mobility. However if a case of active, pulmonary, smear positive tuberculosis is detected in a resident of a long stay hostel, the case should be notified promptly and close contacts of the case screened. ${ }^{20}$

\section{Conclusion}

Tuberculosis remains an important problem among some sections of the homeless in London. Detection, follow up, and treatment of cases of tuberculosis among homeless people should be improved by involving outreach community workers and other agencies working with the homeless. Emphasis should be placed on improved surveillance, treatment, and follow up of tuberculosis in the homeless. The relatively high yield makes regular screening of high risk groups such as those attending the Christmas shelters worthwhile, but the cost effectiveness of regular screening in other homeless groups requires further assessment.

We thank the many radiologists and radiographers who donated their time over Christmas as well as all the volunteers and staff of Crisis. In addition, we would like to express our appreciation for the help and advice provided by Mr M Scothern, Ms A Southern, Dr J Moore-Gillon, Dr D Empey, Dr B Gray, D GM Cochrane, Dr N Jarad, Professor P Fine, Dr PA Jenkins, Dr D Shennan, Dr J Balazs, and Ms M Brancic. Equipment was kindly loaned by Kodak and General Electric.
1 Office of Population Censuses and Surveys. Communicable disease statistics: Statistical tables 1992. Series MB2 No 19. London: HMSO 1994;1-2.

2 Watson JM (editorial). Tuberculosis in Britain today. $B M f$ 1993;306:221-2.

3 Tuberculosis among residents of shelters for the homeless - Ohio 1990. MMWR 1991;40:869-77.

4 Nolan CM, Elarth AM, Barr H, Saeed AM, Risser DR. An outbreak of tuberculosis in a shelter for homeless men: a description of its evolution and control. Am Rev Respir Dis 1991;143:257-61.

5 Paul EA, Lebowitz SM, Moore RE, Hoven CW, Bennett Paul EA, Lebowitz SM, Moore RE, Hoven CW, Bennett
BA, Chen A. Nemesis revisited: tuberculosis infection in a New York City men's shelter. Am F Public Health 1993; 83: $1743-5$

6 Torres RA, Mani S, Atholz J, Brickner PW. Human immunodeficiency virus infection among homeless men in a New York city shelter: association with Mycobacterium tuberculosis infection. Arch Intern Med 1990;150:2030-6.

7 Zolopa AR, Hahn JA, Gorter R, et al. HIV and tuberculosis infection in San Francisco's homeless adults: prevalence and risk factors in a representative sample. $¥ A M A 1994$; 272:455-61.

8 Pablos-Mendez A, Raviglione MC, Battan R, RamosZuniga $\mathrm{R}$. Drug resistant tuberculosis among the homeless in New York City. NY State f Med 1990;90:351-5.

9 Drug resistant tuberculosis among the homeless - Boston. Drug resistant tuberculosis
$M M W R$ 1985;34:429-31.

10 Canter D, Drake M, Littler T, Moore J, Stockley D, Ball J. Faces of homelessness: Interim report to the Salvation Army. Guildford: University of Surrey, 1990;3-4

11 Fisher N, Turner SW, Pugh R, Taylor C. Estimating numbers of homeless and homeless mentally ill people in north east Westminster by using capture-recapture analysis. BMF 1994;308:27-30.

12 Office of Population Censuses and Surveys. 1991 Census preliminary report for England and Wales: Supplementary monitor on people sleeping rough. London: HMSO, 1991 .

13 Shelter. Left out: Sleeping out in severe weather. London: Shelter, 1991.

14 Capewell S, France AJ, Anderson M, Leitch AG. The diagnosis and management of tuberculosis in common diagnosis and management of tuberculosi

15 Joint Tuberculosis Council. Tuberculosis in vagrants and inmates of lodging houses. The Medical Officer 1965;113 $103-4$.

16 Patel KR. Pulmonary tuberculosis in residents of lodging houses, night shelters and common hostels in Glasgow: A five year prospective survey. $\mathrm{Br} \mathcal{F}$ Dis Chest 1985;79: 60-6.

17 Stevens A, Bickler G, Jarrett L, Bateman N. The public health management of tuberculosis among the single homeless: is mass miniature $\mathrm{x}$-ray screening effective? Epidemiol Community Health 1992;46:141-3.

18 Shanks NJ, Caroll KB. Persistent tuberculous disease among inmates of common lodging houses. F Epidemiol Community Health 1984;38:66-7.

19 Schieffelbein CW, Snider DE. Tuberculosis control among homeless populations. Arch Intern Med 1988;148:1843-46.

20 Joint Tuberculosis Committee of the British Thoracic Society. Control and prevention of tuberculosis in the United Kingdom: Code of practice 1994. Thorax 1994;49:1193200. 